\title{
Biofuels for urban transport: Brazilian potential and implications for sustainable development
}

\author{
M. D. Berni, S. V. Bajay \& P. C. Manduca \\ Interdisciplinary Center on Energy Planning, NIPE, \\ University of Campinas, (UNICAMP), State of São Paulo, Brazil
}

\begin{abstract}
This work analyzed potential, implications and experiences for biofuels with ethanol and biodiesel for urban transport in Brazil. Energy use in urban transport has been growing at a faster pace than other areas, a trend that is likely to continue. Transport is also responsible for a major share of air pollution in cities. Environmental and urban transport is a topic of priority for urban authorities and government organizations around the world. The fleet of Brazilian vehicles circulating has expanded from 3 million in 1970 to about 33 million in 2010, 70 percent of which are automobiles. Urban traffic problems are associated with the marked increase in the use of cars, added to an inappropriate public transportation system and heavy truck traffic in central areas. Another issue to be considered in future transportation policies is pollutant emissions, which are intensified through the predominant use of individual vehicles instead of collective ones, and also through increased use of diesel and gasoline, instead of alternative fuels. Brazil is one of the countries with high potential for fuel production from biomass and has already given a good example to the world as how to implement a program and use of biofuel based on renewable energy sources. The Brazilian ethanol program already has 34 years of experience and has produced a mature industry. Biodiesel, in turn, is just in the initial phases, with a chain of production being structured and the search being made for the best solutions from the economic, social and environment standpoints.

Keywords: urban transport, biofuels, ethanol, biodiesel, environment, sustainable development.
\end{abstract}




\section{Introduction}

Worldwide, there is a growing interest regarding the use of liquid biofuels in the transport sector, ethanol and biodiesel being the best short-term alternatives. Rising oil prices, environmental concerns including concerns regarding emissions of greenhouse gases (GHG), and interests in energy security have driven countries to look to biofuels production, ethanol in special, as a potential solution other important driven forces have been the concerns regarding the need to stabilize commodity prices and cut down on agricultural subsidies [1].

The Brazilian vehicles circulating fleet has expanded from 3 million in 1970 to about 33 million in 2010, 70 percent of which are automobiles. Urban traffic problems are associated to the marked increase in the use of cars, added to an inappropriate public transportation system and heavy truck traffic in central areas. Another issue to be considered in future transportation policies is pollutant emissions, which are intensified through the predominant use of individual vehicles instead of collective ones, and also through increased use of Diesel and gasoline, instead of alternative fuels.

\section{Urban transport and biofuels}

Regarding biofuels, the main priorities of developed countries are to reduce GHG emissions in urban transport and diversification of the energy matrix than to put the focus on rural development, jobs creation and saves of foreign currency. An important advantage of biofuels is that the required changes in the existing infrastructure and on the stock of vehicles are minor, including petrol stations. These advantages are even larger when blends of biofuels and fossil fuels are used and if the blends are prepared upstream of the fuel stations. Also for these vehicles the modifications are also relatively small or unnecessary in case of blends with up to 25 percent ethanol [2]. In Brazil, the motors are factory calibrated to a mixture of 22 percent. The oxygen sensor works with a range of tolerance, yet the change will cause a small increase in fuel consumption, estimated at around 2 percent [3]. The Brazilian ethanol experience is so far much more important than with biodiesel. Scenario different from that in Europe where the prospects for biodiesel use are much better fuel than ethanol due to the availability of the feedstock [1].

Transport problems resulting from urban sprawl, incoherence in the localization of diverse activities and vehicle overuse require complex systemic solutions that could be difficult to implement in the short term. Such solutions must be provided by an integrated urban planning and mainly by the state's regulatory policies to revert cities' sprawl tendency while also privileging compactness over sprawling, multimodality over the hegemony of motor transport and collective transport over private transport means.

In Brazil the railroads prevails over other modes of transportation. Recent statistics are lacking, but it is estimated that currently the road transport accounts for 65 percent of the total cargo transported in the country The State of São Paulo, responsible for 33.4 percent of Brazilian GDP has an array of 
transportation even more distorted, with 93.3 percent of its economic wealth being transported by road, rail by 5.5 percent and 1.2 percent by other modes.

In the Brazilian urban transport sector, 25 percent of demand for transport is not fully met, and among users of public transport 27.5 percent, or 55 million people are excluded from access to public transportation. A few use bicycles and the vast majority is walking. Thus, the 204 million daily trips in Brazil, at distances over 500 meters, 43.6 percent are made on foot, by proportion of the population has no access to transportation vouchers - live in informality - or resources to pay the price of public transport [4]. This is the portrait of the great urban centers of the country biofuels, if used for public transportation can alleviate this picture of moral and social wear? In Rio de Janeiro, research done by the Department of Sociology, State University of Rio de Janeiro shows that out of every four residents of the streets, have a place to live, but will not go away in the day because it has no money to pay for transportation. He goes home only on weekends and returns to work on Monday. They are street vendors, street vendors who work the streets, keep your workplace, sleep there and come back on Friday to have the family life. These people are excluded from the transport of citizenship. Biofuels can be mixed with gasoline or diesel in simple or nearly pure (e.g. mixture of E25 ethanol). On However, the latest require a modification of vehicle components and distribution infrastructure such as ducts, tanks and fuel dispensers. This could be a barrier to use.

\subsection{Biodiesel}

Biodiesel is mainly represented by the crude oil derived from some plant species. It presents very interesting advantages, such as the real possibility of replacing nearly all the petroleum in unmodified engines, eliminating dependence on oil. In this context, the Brazilian government have stimulated the production and marketing of biodiesel and is the main landmark publication of Decree No. 5448 on May 20, 2005, which regulated Law number 11.097 of January 2005, which provides for the introduction of biodiesel in the Brazilian energy matrix, setting the minimum mandatory addition of biodiesel to diesel oil sold to final consumer, anywhere in the country [5].

Globally, through partnerships with the private sector and research centers, Argentina, United States, Germany, France, among others, has been producing biodiesel on a commercial scale and testing its feasibility in individual vehicles and public transport.

The use of biodiesel fuel in road transport could minimize problems such as energy dependence of population isolation and self-sufficiency, provide conditions for economic development areas considered miserable, reflecting the decrease in migration to large cities, improvement of environmental conditions in large urban centers, with the decrease in pollutant emissions of GHG and respiratory diseases. Importantly, each region would have its own program as the production characteristics vary at each location, in the face of climate, vegetation, soil type and topography. On the other hand, it is imperative to establish quality standards similar to those found in international biodiesel to its 
full acceptance in the market and efficient use of road transport fuel, displacing the traditional petroleum products: gasoline and Diesel oil.

Biodiesel, by contrast, is still an infant industry in Brazil, and biodiesel policies are much more recent. The biodiesel law of 2005 established minimum blending requirements of 2 percent and 5 percent to be accomplished by 2008 and 2013, respectively. Reflecting social inclusion and regional development concerns, a system of tax incentives was established for the production of raw materials for biodiesel on small family farms in the north and northeast regions of Brazil. Under a special scheme, the "Social Fuel Seal" programme, biodiesel producers who buy feedstocks from small family farms in poor regions pay less federal income tax and can access finance from the Brazilian Development Bank. The farmers are organized into cooperatives and receive training from extension workers [6].

\subsection{Ethanol}

Brazil is the world's largest ethanol producer and a pioneer in using ethanol as a motor fuel. In 2010, Brazilian ethanol production reached 27.4 billion liters (7.2 billion gallons). Most of this production is absorbed by the domestic market where it is sold as either pure ethanol fuel or blended with gasoline. All gasoline sold in Brazil includes a blend of 18 to 25 percent ethanol. Ethanol is an alcohol based fuel produced by the fermentation of sugarcane juice and molasses.

Because it is a clean, affordable and low carbon biofuel, ethanol has emerged as a leading renewable fuel for the transportation sector. Ethanol can be used blended with gasoline at levels ranging from 5 to 25 percent to reduce petroleum use, boost octane ratings and cut tailpipe emissions and pure ethanol, a fuel made up of 85 to 100 percent ethanol depending on country specifications (anhydrous or hydrated) and specially designed engines.

The country first began using ethanol in vehicles as early as the 1920s, and the trend gained urgency during the oil shock of the 1970s. However, sugarcane ethanol's popularity really took off in 2003 with the introduction of flex fuel vehicles (FFV) that run on either gasoline blends or pure ethanol. FFVs give Brazilian consumers a choice at the pump when they fuel their cars, and most are choosing sugarcane ethanol for its price and environmental benefits. Since 2008, annual ethanol sales have surpassed that of gasoline in Brazil, making gasoline the alternative fuel in the country. Since 2003, the combination of sugarcane ethanol and flex fuel vehicles has reduced Brazil's emissions of carbon dioxide by 122 million tons. That's as good for the environment as planting and maintaining 873 million trees for 20 years [2]. More than 90 percent of new cars sold today in Brazil are flex fuel due to consumer demand, and these vehicles now make up about half of the country's entire light vehicle fleet - a remarkable accomplishment in less than a decade. Currently, 12 automakers offer over 90 models of FFVs in Brazil (Figure 1). 


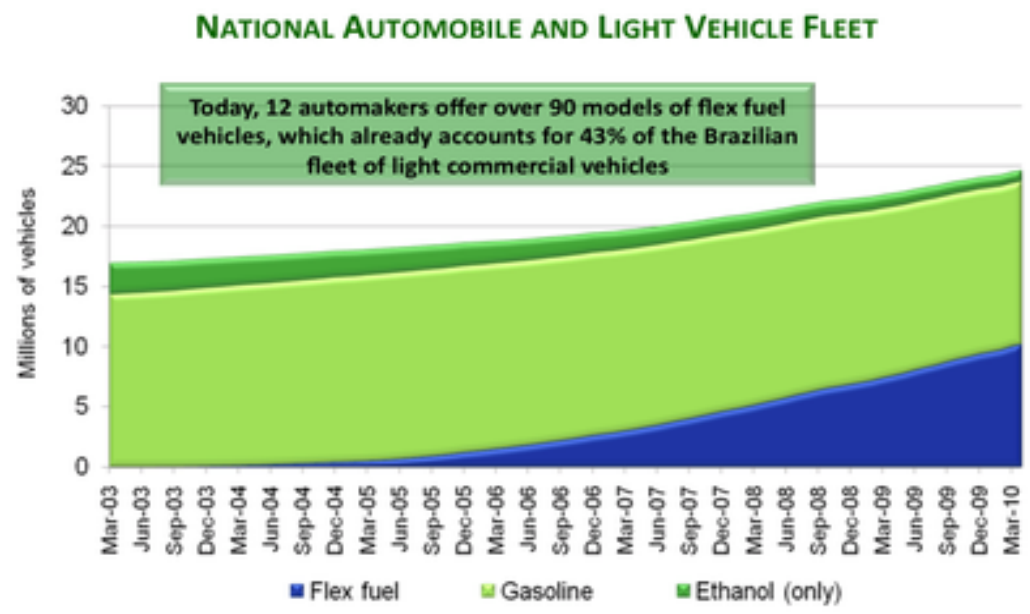

Source: [2]

Figure 1: National automobile and light vehicle fleet.

As a result, Brazilian consumers have a choice at the pump when they fuel their cars and most are choosing sugarcane ethanol for its price and environmental benefits. Market projections suggest that FFV sales will tend to stabilize at around 90 percent, with the rest being diesel-powered light vehicles and gasoline-powered imported models that do not offer the flex fuel option.

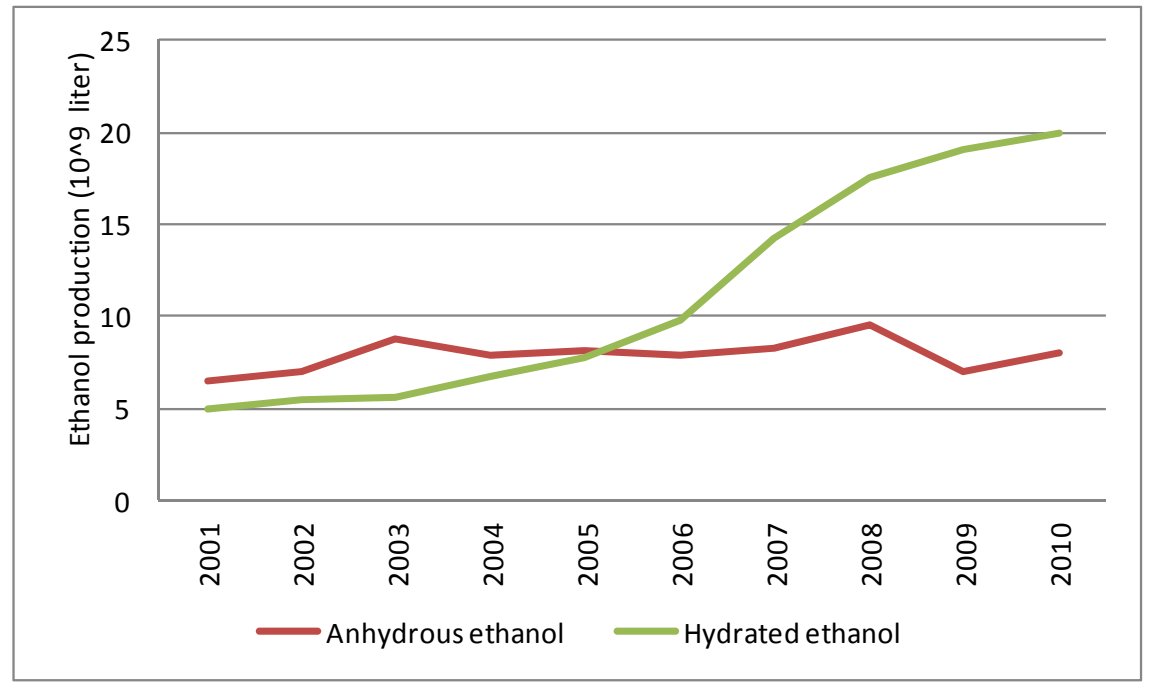

Source: [7]

Figure 2: $\quad$ Fuel ethanol production in Brazil from 1970 to 2006. 
In comparison with neat ethanol vehicles, the main advantage of the FFVs is that these engines can operate with any fuel mix between gasoline (in Brazil, E20-E25) and pure hydrated ethanol (E100). The success on sales of FFVs and the relative low price of ethanol vis-à-vis gasoline are the reasons why it is predicted that the domestic ethanol market will increase even further in the future. In 2010 ethanol production (anhydrous + hydrated) has reached 27,9 G1 [7] and the estimates for 2011 are 25,4 Gl [2]. Figure 2 shows the evolution of fuel ethanol production in Brazil since 2001.

The capacity of ethanol production through conventional technologies and feedstocks was shown by Walter et al. [1]. The estimates of fuel ethanol production through conventional technologies and feedstocks for 2010-2030 are presented in Table 1.

Table 1: Estimates of fuel ethanol production, conventional technologies 2010-2020-2030 (giga liters).

\begin{tabular}{|c|c|c|c|}
\hline Country & $\mathbf{2 0 1 0}$ & $\mathbf{2 0 2 0}$ & $\mathbf{2 0 3 0}$ \\
\hline USA & 26.0 & 45.2 & 64.2 \\
\hline Brazil & 26.0 & 44.7 & 62.0 \\
\hline World & 67.5 & 131.0 & 182.0 \\
\hline
\end{tabular}

Source: [1]

\section{Final considerations}

The worsening of the urban crisis in the country and the political, social and economic conditions that currently take place on a global scale, require a new effort of organization of cities and their transportation systems. In this context, the reorientation of the energy matrix transport through the introduction of fuels such as ethanol and biodiesel, make the effort of searching for sustainable cities more pleasant and feasible in the medium term, on Brazil.

The processes of economic development and transport model in use have worsened traffic conditions in cities, causing great diseconomies and compromising the quality of life. Thus, the efficiency of the Brazilian economy will largely depend on the proper functioning of this network of cities and their transportation systems. Thus, the improvement of economic and environmental performance in large cities is linked directly to changes in progress for the viability of a sustainable energy matrix for transport. It is essential to change the logic of the current energy mix of urban transport, too. Today, the costs of the current energy model for the urban transport fall, particularly on passengers by increasing fares. In addition to environmentally and socially unacceptable, an important obstacle in the strategic point of view. The permanence of the current model is not compatible not only with a better quality of life in a truly democratic society, but in preparing the country for the new conditions of economic competition on a global scale.

It is generally agreed the urgency and importance of adopting a new model of sustainable cities in Brazil, anchored in the public transport system and the use 
of biofuels and, where possible focus subways, light rail and bike paths to replace the use of private transport, which makes mobility in large and medium cities. The 2014 World Cup and 2016 Olympic Games are events that can mean the opportunity to implement a model of urban mobility more humane and environmentally sustainable. Obviously that biofuels will not be the unique solution, but may contribute to solve some of the problems that the world needs to address urgently reduction of GHG emissions, improving air quality in Brazilian large cities. In transports biofuels are one of the alternatives. Brazil is the world leader in producing ethanol from sugar cane. Prejudice against imports of Brazilian ethanol markets is unjustified, as it represents the best ecological balance and does not reduce production of basic food in Brazil. As to biodiesel on the basis of soybeans social and ecological reserves partly are in order. Regarding ethanol industrialized countries should not use exaggerated criteria as to sustainability of production as pretext for protecting their own producers from imports of cheaper Brazilian biofuels. Furthermore the biodiesel program of the Brazilian government was designed to be an antidote to the crisis experienced by small and medium farmers. The government's goal is to associate the production of vegetable oils for income generation programs in the field using Petrobras. Thus the company would buy the vegetable oils and would use in biodiesel production. In the current phase, searches of Petrobras failed to define the best oleaginous plants to be grown in large.

\section{References}

[1] Walter, A., Rosillo-Calle, F., Dolzan, P., Piacente, E. \& Cunha, K.B.d, Task 40 Sustainable Bio-energy Trade; securing Supply and Demand, Deliverable 8 Market Evaluation: Fuel Ethanol, 2007.

[2] UNICA, Sugarcane Industry Association, http://english.unica.com.br/, accessed in 2011/12/15.

[3] AEA, Association of Brazilian Automotive Engineering, http://www.aeabrazil.com/, accessed in 2011/11/20.

[4] ANTP, National Association of Public Transport, (ANTP), http://www.antp.org.br, accessed in 2012/01/05.

[5] Brazil, Governo Federal, http://www.planalto.gov.br, accessed in 2012/01/03.

[6] WRI, World Resources Institute, Growing in the Greenhouse Protection the Climate, Edited by: Rob Bradley, Kevin A. Baumert, In collaboration with: Navroz K. Dubash, José Roberto Moreira, Stanford Mwakasonda, WeiShiuen Ng, Luiz Augusto Horta Nogueira, Virginia Parente, Jonathan Pershing, Lee Schipper, Harald Winkler, 2005.

[7] EPE, Empresa de Pesquisa Energética, Brazilian Energy Balance 2011 Year 2010, Ministry of Mines and Energy. Brasília; 2011, Available at www.mme.gov.br. 